\title{
Retraction Note to: Therapeutic effects of metformin and laparoscopic ovarian drilling in treatment of clomiphene and insulin-resistant polycystic ovary syndrome
}

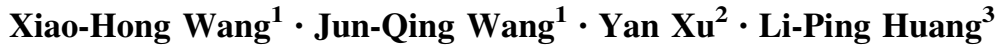

Published online: 29 January 2016

(C) Springer-Verlag Berlin Heidelberg 2016

\section{Retraction to: Arch Gynecol Obstet (2015)}

291:1089-1094

DOI 10.1007/s00404-014-3486-z

This article has been retracted by the Editor-in-Chief, with the agreement of the authors, because it contains significant parts plagiarizing another article: Hamed HO, Hasan AF, Ahmed OG, Ahmed MA. Metformin versus laparoscopic ovarian drilling in clomiphene- and insulin-resistant women with polycystic ovary syndrome. Int J Gynaecol Obstet 2010;108:143-147. doi:10.1016/j.ijgo.2009.08.033.

The online version of the original article can be found under doi:10.1007/s00404-014-3486-z.

Li-Ping Huang

lipinghuangcn@126.com

1 Department of Obstetrics and Gynecology, 101st Hospital of PLA, Wuxi 214044, China

2 Department of Endocrinology, 101st Hospital of PLA, Wuxi 214044, China

3 Department of Obstetrics and Gynecology, Nanfang Hospital of Southern Medical University, Guangzhou 510515, China 